\title{
Politics, Responsibility and Risk: Editorial Introduction
}

\author{
by Elizabeth Ettorre and Alison Anderson \\ University of Liverpool; University of Plymouth
}

\author{
Sociological Research Online, Volume 12, Issue 2, \\ < http://uww. socresonline.org.uk/12/2/ettorre. $h t m />$ \\ doi:10.5153/sro. 1539
}

Received: 20 Mar 2007 Accepted: 21 Mar 2007 Published: 30 Mar 2007

\section{Introduction}

1.1 The papers in this special issue of Sociological Research Online were all presented the British Sociological Association Annual Conference, held at the University of York in March 2004. The conference theme was 'Sociological Challenges: Conflict, Anxiety and Discontent'. This is the second special issue of Sociological Research Online to emerge from that conference. The first special issue, 'Families, Intimacy and Social Change', was published in SRO last June 2006 (See Sociological Research Online, Volume 11, Issue 2, http://www.socresonline.org.uk/11/2/editorial.html for a fuller discussion of the conference focus, selection of papers, themes, etc.).

1.2 In this editorial we look briefly at the five papers selected under the theme, 'Politics, Risk and Responsibility'. The politics of risk is a topic which is impossible to overlook. Indeed, the concept of risk is highly politicised (Caplan 2000) and a much used (perhaps, overused) category in sociology. While we know the study of risk reveals an enormous amount about key elements of modernity, the quintessential risk culture (Beck 1992; Giddens 1991), the concept of risk assumes human responsibility - that something can be done to prevent misfortune or frightening events (Lupton, 1999: 3). Contemporary work on risk exposes the unease that awareness of deviations from the norm create.

1.3 This special issue begins with the paper, 'I love you to the bones: Constructing the anorexic body in the 'Pro-Ana' Message Boards' by Katie Ward. This is a fascinating piece which challenges both medical and social models concerning appropriate body shape and size as well as approaches to the 'treatment' of anorexia. Ward presents an alternative approach which is anti-medical, as well as an ethnography of the pro-anorexia community which is 'risk adverse'. The key question she poses is, 'How is it possible for anorexics, labelled as pathologically thin, to reject the medical model in favour of a disciplinary regime which guarantees stability and control as well as a 'healthy diet' of pills and purging, sustaining life? One answer to this question is that pro-ana participants (low body weight individuals) share important information on various websites on the Internet. This information helps to alter radically the meaning of weight loss pharmaceuticals and allows them to become 'expert patients' who not only resist medical definitions of health and illness but also employ pharmaceutical technologies in ways never intended by government, physicians and the pharmaceutical industry.

1.4 The second paper 'The body as a weapon: Bobby Sands and the Republican hunger strikes' by Chris Yuill explores the politics of risk through the lens of prisoners' bodies in 1970-1980s Northern Ireland. Yuill theorises how these incarcerated in 'H-Block' bodies were used as modalities of resistance and how, through hunger strikes, prisoners' bodies were mobilised as a resource and weapon to destabilise notions of civilised embodiment. The bodily suffering the prisoners endured in the form of hunger strikes, privation and psychological misery contributed to notions of self-sacrifice and martyrdom which were embedded in the tradition of Catholicism and Gaelic heroes. Key to this paper is how the 'risky 'body emerges in political arenas particularly when hostility and struggle are present.

1.5 The need for a clear feminist approach on the experience of women who have been sexually abused in childhood is addressed in the third paper, 'Poliitics, responsibility and adult victims of childhood sexual abuse' by Jo Woodiwiss. This is an empirically based paper, which includes interviews and written accounts from sixteen women with continuous, recovered or false memories of sexual abuse in childhood. Reviewing 'the harm story' versus 'the healing discourse' in this therapeutic world, Woodiwiss contends that both are based on similar models of childhood and development, namely that women who are sexually abused are unable to develop into healthy adults. The implication is that these women see themselves as sick, damaged and responsible for their lack of joy. Ironically, while Woodiwiss's respondents wanted to experience themselves as 'normal', the experience of normality for some was impeded by their therapeutic or counselling relationships. Furthermore, in their awareness of the supposed need to recognise 'an inner child', they created a variety of ways of dealing with this awareness ranging from acceptable to non- 
acceptable from a therapeutic point of view. Woodiwiss skilfully unpicks the discourses surrounding continuous, recovered or false memories syndromes and concludes that when these risky discourses don't work, as is often the case, women should be offered alternative perspectives informed by feminism. For her, approaches that are not informed by feminist discourses are imbued with risk.

1.6 David Clark's paper 'Sites of memory or aids to multiculturalism?: conflicting uses of Jewish Heritage sites' is the fourth paper in this selection. Clark's work is based on an empirical study of four Jewish museums in Italy (Venice, Florence, Ferrara and Bologna) from 1999-2002. This particular paper focuses on his work with the Jewish Museum in Bologna. His main argument is that establishing a Jewish museum in Bologna was not only about the marking of a Jewish space in the politics of memory of a nation, but also establishing the museum as a 'contact zone' in a deliberate attempt to re-colonise the Bologna (Jewish) ghetto and to re-claim it as a Jewish space. Clark unpicks the public's interest in the establishment of a didactic (i.e. educational) focused museum, as opposed to an aesthetic focused one, as a form of contrition at the treatment of Jews under Italian fascism. For Clark, this didactic focus allows the difficult issues of immigration and multiculturalism to be fore grounded. But sadly, as Clark points out, the didactic focus is mainly related to the past leaving little room for interpretations of anti-semitism and more importantly, anti-racism in the present. Here, the message is clear - focusing on the present injustices related to the issues of multiculturalism and pluralism is seen as too risky for the Bologna community and Italian state.

1.7 The last paper in this selection is by a group of authors, Rose Wiles, Graham Crow, Vikki Charles and Sue Heath and it is entitled, 'Informed consent and the research process: following rules or striking balances?. This paper aids an understanding of how researchers manage issues of informed consent and was based on an empirical study of academic and non-academic researchers who conduct qualitative research on or with 'vulnerable groups of respondents'. The authors highlight two difficulties which arise when researchers seek informed consent. Firstly, there is not unanimous agreement on what informed consent is and secondly, no consensus exists on whether or not similar sets of principles and procedures apply to different groups and different methodologies. The conclusion was that researchers wanted guidelines that facilitated them in striking a balance between conflicting pressures that happen when one does research. Here, the politics of responsibility in doing ethical research is shaped by the risks of making the right balance between protection of subjects and researcher vulnerability.

1.8 While the papers in this special issue deal with this issue of risk, they do so in a variety of ways through challenging the hegemony of risk in the anorexia discourse (Ward); seeing the risky prisoner's body as a site of resistance (Yuill); the risk of using non-feminist discourses in understanding continuous, recovered or false memories syndromes (Woodiwiss); the contemporary risk of educating communities on multiculturalism (Clark) and balancing risk and responsibility in carrying out research on human subjects (Wiles et. al.). All of these contributions provide us with a series of empirically based studies that tackle the intricacies of the contemporary politics surrounding the responsibilities and risks of everyday social life. We thank the contributors for making this special issue such an interesting collection and the reviewers who helped in reviewing of papers for this special issue. We hope you, the readers, will find these empirical and theoretical explorations worthwhile and use them as references in your future work on the sociology of risk.

\section{Professor Elizabeth Ettorre (Professor of Sociology, University of Liverpool) Dr Alison Anderson (Reader in Sociology, University of Plymouth)}

\section{References}

BECK, U. (1992) Risk Society: Towards a New Modernity. London: Sage.

CAPLAN, P. (2000) Introduction: Risk Revisited, In P. Caplan (Ed.) Risk Revisited, London, Pluto Press.

GIDDENS, A. (1991) Modernity and Self-Identity: self and society in the late modern age ,Cambridge, Polity Press.

LUPTON, D. (1999) Risk. London, Routledge. 